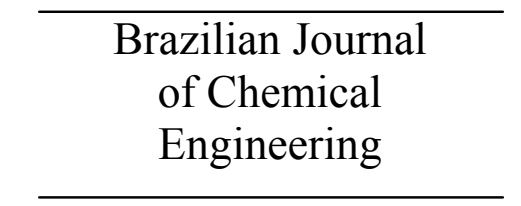

ISSN 0104-6632

Printed in Brazil

www.abeq.org.br/bjche

Vol. 25, No. 04, pp. 765 - 776, October - December, 2008

\title{
DYNAMIC OPTIMIZATION OF THE BENZENE EXTRACTIVE DISTILLATION UNIT
}

\author{
A. Ghaee, R. Sotudeh-Gharebagh ${ }^{*}$ and N. Mostoufi \\ Process Design and Simulation Research Center, Department of Chemical Engineering, \\ Faculty of Engineering, Fax: +98(21) 6646-1024, \\ University of Tehran, P.O. Box 11365-4563, Tehran, Iran. \\ E-mail: sotudeh@ut.ac.ir
}

(Received: February 1, 2007 ; Accepted: March 2, 2008)

\begin{abstract}
A mathematical model has been developed for describing the dynamic operation of the $\mathrm{N}$ formylmorpholine extractive distillation column and the corresponding solvent recovery column in the benzene extraction plant. The NRTL equation was used to calculate the equilibrium and thermodynamic properties of the mixtures. The validity of the model in terms of temperature, pressure and split fraction was examined using actual plant data at steady-state conditions. Comparison between model results and plant data shows good consistency. In order to improve the control of the process and selection of the optimal control strategy, the model was used to find the optimum values of the constants of the controllers with Nelder-Mead algorithm during unsteady-state operation by minimizing the deviation from steady-state conditions. The outcome of this study could be used by operators and engineers to increase the productivity of the unit.

Keywords: Benzene extractive distillation; Process modeling; Dynamic optimization; N-formylmorpholine (NFM).
\end{abstract}

\section{INTRODUCTION}

There are great demands for highly pure aromatics, which are products of catalytic naphtha reforming, as feedstock in petrochemical industries. Extractive distillation units with nonpolar solvents, such as N-formylmorpholine (NFM) (CAS no. 4394$85-8$ ), is often used to separate aromatics from reformates. This is a common practice for separation of the components in homogenous azeotropic mixtures or components with close boiling points that are either difficult or improbable to separate by conventional distillation techniques. In the extractive distillation process, a heavy boiling, relatively nonvolatile solvent is fed into a tray above the main feed stream. The extractive solvent creates or alters the volatility difference between the components to be separated. These interactions occur predominantly in the liquid phase (Ko et al., 2002 a). The solvent is continuously added near the top of the extractive distillation column so that a considerable amount of solvent would be present in the liquid phase on all trays.

There are numerous references concerning steady-state and dynamic simulation of extractive distillation columns. For instance, Munoz et al. (2006) simulated separation of isobutyl alcohol and isobutyl acetate, using butyl propionate as the solvent. Steltenpohl et al. (2005) used the HYSYS ${ }^{\odot}$ (Hyprotech Ltd., USA) process simulator for the simulation of extractive distillation of a ternary mixture of toluene, heptane and NMethylpyrrolidone (NMP). Pradhan and Kannan (2005) reported simulation of the extractive valve tray column. The steady-state simulation of a saline extractive distillation column for production of absolute ethanol was reported by Llano-Restrepo and Aguilar-Arias (2003). The dynamic simulation and control strategy of extractive distillation has been reported by Jimenez and Costa-Lopez (2002). Nevertheless, only Ko et al. (2002 b) have reported simulation of an aromatic recovery process by

*To whom correspondence should be addressed 
extractive distillation using NFM as the solvent. In some dynamic cases, the product may become offspec where the disposal would be rather costly (Wozny and Li, 2004). Such a drawback could be overcome by optimization if the process reaches steady-state as fast as possible.

Dynamic optimization is an increasingly important aspect in energy and chemical industries. Start-up, shut-down and feed changeovers are frequent operations in chemical industries and the demand for more flexible processes that can better handle such operations is increasing. These dynamic events could be subject to optimization in order to find the optimum trajectories. Optimization attempts have been reported for extractive distillation processes by Langston et al (2005), Low and Sorensen (2002) and Munoz et al (2006). However, none deals with extractive distillation of benzene by NFM. In the present study, a dynamic model has been developed for the extractive distillation of benzene by the NFM solvent. The dynamic optimization techniques were applied for the purpose of reaching fast steady state conditions where the calculation of the control parameters becomes possible in the event of feed disturbances.

\section{PROCESS DESCRIPTION}

The industrial benzene extraction plant, shown in Figure 1, consists of three main sections, which are pre-distillation, extractive distillation and solvent regeneration. In the pre-distillation section, the feed (consisting of benzene and non-aromatics) is separated to toluene and benzene fractions. The benzene fraction enters the extractive distillation column, being recovered using the NFM solvent. In fact, adding NFM as solvent alters the vapor pressure, facilitating paraffins and naphthenes (i.e., non-aromatics) removal by distillation from aromatics. The vapors at the overhead of the extractive distillation column, containing nonaromatics and a small amount of benzene and solvent, are fed into the solvent recovery column, where solvent and non-aromatics are separated. The bottom product of the extractive distillation column, consisting of solvent, benzene and a small amount of non-aromatics, is conveyed to the stripper column, in which pure benzene is obtained as the overhead product by vacuum distillation (solvent regeneration unit). The stripped hot solvent from the bottom of the stripper column is pumped through several heat exchangers to the top of the extractive distillation column. In this research, the extractive distillation section was the subject of the dynamic optimization.

\section{Extractive Distillation Section}

The extractive distillation section itself consists of two units: extractive distillation column and solvent recovery column, as shown in Figure 2. In the extractive distillation column, non-aromatics are separated from benzene. This separation is impossible under normal conditions by means of distillation. NFM, the solvent, which is fed to the top of the extraction distillation column, makes it possible to selectively absorb and separate nonaromatics and benzene. The solvent recovery column is used for separation of the non-aromatics present at the top of the extractive distillation column from the residual solvent. A portion of the bottom is fed to the solvent separator in order to recover NFM. The solvent separator splits the liquid into two liquid phases. The non-aromatic-rich phase is returned to the Solvent Recovery Column; while the NFM-rich phase is directed to the ED Column (lean solvent circuit). The solvent recovery column in combination with the solvent separator reduces the use of NFM. This section is controlled by pressure, temperature and level controllers.

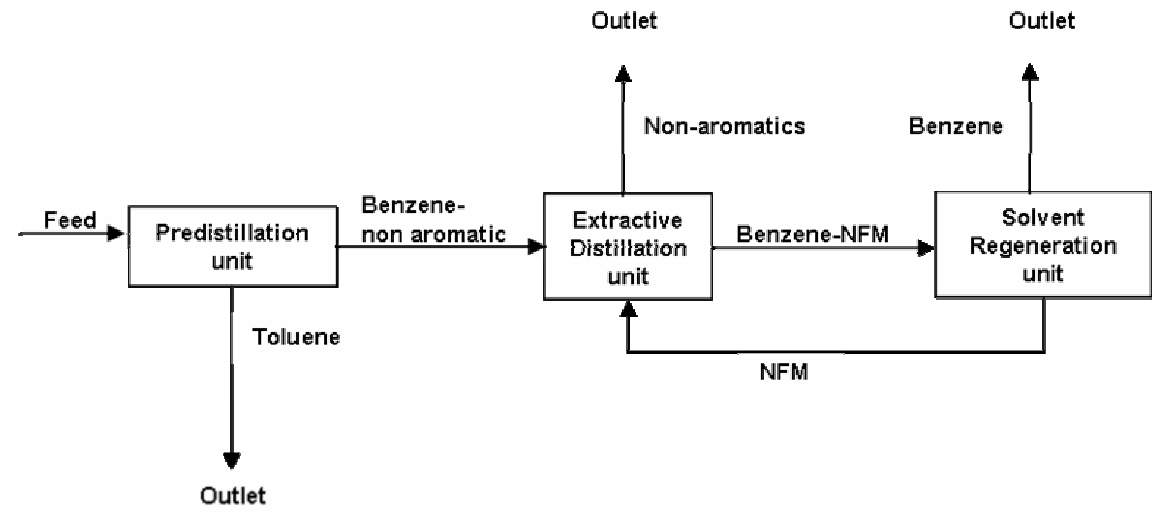

Figure 1: Block flow diagram of benzene extraction plant 


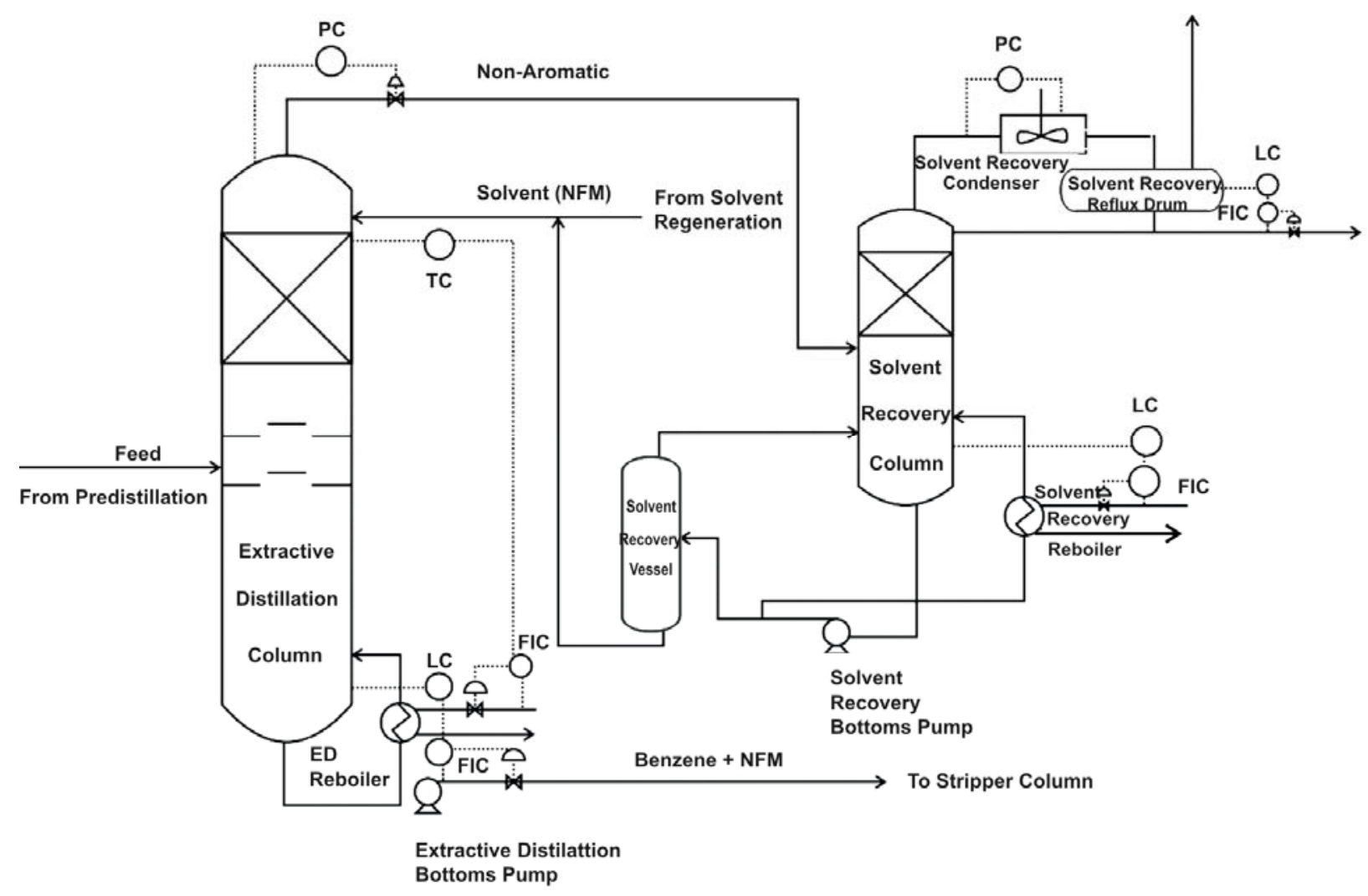

Figure 2: Process flow diagram of extractive distillation section

Automatic control of the extractive distillation column includes the operation of the solvent recovery column, the function of which always has to be considered in conjunction with the extractive distillation column. Reliable operation of the extractive distillation column is achieved by employing the following three controllers:

a) Overhead pressure controller: This controller influences the overhead pressure of the extractive distillation column. Input signal to this controller is the overhead pressure signal, which changes the flow rate of the overhead vapor exiting the column in order to maintain the pressure at set point. In fact, an increase in the overhead pressure is a result of accumulation of vapor at the top of the column. Therefore, the valve should be opened in this case, allowing the vapors to leave the column, reaching the pressure determined by the set point. If the pressure decreases, the valve would become close and the vapors accumulate in the column, resulting in an increase in pressure.

b) Overhead temperature controller: Flow of the overhead vapors is influenced by the thermal balance in the extractive distillation column. Since the vapor flow is very small compared to the bottom product flow, slight changes in solvent temperature cause significant changes in the vapor flow. The extractive distillation column is very sensitive to the heat balance, i.e., vapor flow rates could change remarkably when the net heat to the column changes. Higher temperature of NFM or hydrocarbon feed stock in extractive distillation causes higher vapor flow at constant reboiler duty. Close controlling of heating duty of the reboiler is an essential prerequisite for normal operation of the column. Therefore, this controller maintains the overhead temperature by influencing the duty of the reboiler reversely through changing the flow of the steam.

c) Bottom level controller: This controller maintains the liquid level in the bottom section of the column. When the liquid level is low, the control valve on the liquid output of the column would be closed in order to keep the liquid inside the column until the level reaches the desired point.

Safe operation of the solvent recovery column is also ensured by the following controllers: 
a) Overhead pressure controller: Overhead pressure of the column is controlled by direct change in the duty of the condenser. If the pressure is increased, this would lead to an increase in the air flow rate of the air cooler and the duty of the condenser, so vapor is condensed and vapor accumulation on the top of the column and top pressure are decreased accordingly.

b) Overhead level controller: Liquid level in the reflux drum is controlled by the flow rate of the overhead product of the column. Liquid level changes directly with the flow rate of the product. This controller with the flow controller of overhead product forms a cascade control structure.

c) Bottom level controller: liquid level in the bottom of the column is controlled directly by the flow rate of the bottom product. When the level decreases, the valve would be close and let the liquid accumulate in the column.

\section{MODEL DEVELOPMENT}

In this case, a set of ordinary differential equations has to be solved to find the dynamic response of the plant to the changes in operating conditions. In this section the hypothesis and necessary equations for developing the steady-state and dynamic models of benzene extraction section are described. The typical feed composition for the extractive distillation unit is given in Table 1.

\section{Thermodynamics}

Accurate liquid-liquid equilibrium calculation is essential when dealing with separation processes. For a nonideal chemical system, binary thermodynamic systems are usually employed. Based on the liquid-liquid equilibria data for the systems containing NFM, Ko et al. (2002 a) have shown that the NRTL model correlates these data properly. Therefore, the NRTL activity model was used in the present study for the liquid phase with the binary interaction coefficient reported by Ko et al. (2002 a). Moreover, the Peng-Robinson equation of state was used to predict the fugacity coefficient of the vapor because of the absence of NFM in this phase.

\section{Hypotheses}

Modeling of the extractive distillation section in this study was done based on the following assumptions:

a) Vapor and liquid are completely mixed in each stage and assumed to be at equilibrium.

b) Heat of mixing can be neglected.

c) Condenser and reboiler were considered as equilibrium stages.

d) Vapor holdup is negligible compared to the total holdup on each tray; therefore, variation of pressure could be neglected on each tray.

\section{Model Equations}

The equations of the model, describing the dynamic behavior of all components of the extractive distillation section, are listed in Table 2. The trays in each column, shown in Figure 3, are numbered from bottom to the top. It is obvious that, in the steadystate simulation, the changes in the liquid holdup of the trays have to be neglected. The control system used in this study is analog. The controllers are assumed to be proportional-integral (PI), which are particularly common, since the derivative action is very sensitive to measurement noise, and the absence of an integral value prevents the system from reaching its target value due to the control action. These points are clarified in the manuscript.

Table 1: Properties of feed components (Wauquier (1995))

\begin{tabular}{|l|c|c|c|c|c|}
\hline Component & $\begin{array}{c}\text { Mass Flow } \\
(\mathbf{k g} / \mathbf{h r})\end{array}$ & $\begin{array}{c}\mathbf{T}_{\text {NBP }} \\
\mathbf{( K )}\end{array}$ & $\begin{array}{c}\text { Density } \\
\left(\mathbf{k g} / \mathbf{m}^{\mathbf{3}}\right)\end{array}$ & $\begin{array}{c}\mathbf{T}_{\mathbf{c}} \\
(\mathbf{K})\end{array}$ & $\begin{array}{c}\mathbf{P}_{\mathbf{c}} \\
(\mathbf{b a r})\end{array}$ \\
\hline Propane & 2.21 & 231.07 & 507.0 & 369.85 & 42.48 \\
n-Butane & 0.04 & 272.64 & 584.0 & 425.16 & 37.97 \\
Cyclopentane & 137 & 322.4 & 760.3 & 511.8 & 45.03 \\
2-Methylpentane & 95.62 & 333.4 & 654.8 & 497.5 & 30.11 \\
n-Hexane & 106.57 & 341.9 & 663.8 & 507.5 & 30.13 \\
Cyclohexane & 435.98 & 353.9 & 783.5 & 553.5 & 40.76 \\
Benzene & 7117 & 353.3 & 882.9 & 562.2 & 48.99 \\
n-Heptane & 0.26 & 371.6 & 688.2 & 540.2 & 27.37 \\
Methylcyclohexane & 11.85 & 374.1 & 774.8 & 572.2 & 34.72 \\
Toluene & 0.05 & 383.8 & 874.3 & 591.8 & 41.10 \\
\hline
\end{tabular}


Table 2: Model equations

\begin{tabular}{|c|c|c|}
\hline Section & Equation & $\begin{array}{l}\text { Description } \\
\end{array}$ \\
\hline \multirow{2}{*}{$\begin{array}{l}\text { Extractive distillation and } \\
\text { solvent recovery columns at } \\
\text { stage } \mathrm{j}\end{array}$} & $\mathrm{y}_{\mathrm{i}, \mathrm{j}}=\mathrm{K}_{\mathrm{i}, \mathrm{j}} \mathrm{x}_{\mathrm{i}, \mathrm{j}}$ & $\begin{array}{l}\text { Vapor liquid equilibrium for } \\
\text { each component }\end{array}$ \\
\hline & $\sum_{i=1}^{n} x_{i, j}=1, \quad \sum_{i=1}^{n} y_{i, j}=1$ & Stoichiometric constraints \\
\hline \multirow{3}{*}{$\begin{array}{l}\text { Extractive Distillation Column } \\
\text { at stage } \mathrm{j}\end{array}$} & $\frac{d M_{j}}{d t}=V_{j+1}-V_{j}+L_{j-1}-L_{j}+F_{j}-S_{j}^{V}-S_{j}^{L}$ & Total mass balance at stage $\mathrm{j}$ \\
\hline & $\begin{array}{l}\frac{d M_{j} x_{i, j}}{d t}=V_{j+1} y_{i, j+1}-V_{j} y_{i, j}+L_{j-1} x_{i, j-1}- \\
L_{J} x_{i, j}+F_{j} z_{i}-S_{j}^{V} y_{i, j}-S_{j}^{L} x_{i, j}\end{array}$ & $\begin{array}{l}\text { Component mass balance at } \\
\text { stage } \mathrm{j}\end{array}$ \\
\hline & $\begin{array}{l}\frac{\mathrm{dM}_{\mathrm{j}} \mathrm{H}_{\mathrm{i}, \mathrm{j}}}{\mathrm{dt}}=\mathrm{V}_{\mathrm{j}+1} \mathrm{H}^{\mathrm{V}}{ }_{\mathrm{j}+1}-\mathrm{V}_{\mathrm{j}} \mathrm{H}^{\mathrm{V}}{ }_{\mathrm{j}}+\mathrm{L}_{\mathrm{j}-1} \mathrm{H}_{\mathrm{j}-1}^{\mathrm{L}}- \\
\mathrm{L}_{\mathrm{j}} \mathrm{H}^{\mathrm{L}}{ }_{\mathrm{j}}+\mathrm{F}_{\mathrm{j}} \mathrm{H}_{\mathrm{j}}^{\mathrm{F}}-\mathrm{S}_{\mathrm{j}}^{\mathrm{V}} \mathrm{H}^{\mathrm{V}}{ }_{\mathrm{j}}-\mathrm{S}_{\mathrm{j}}^{\mathrm{L}} \mathrm{H}_{\mathrm{j}}^{\mathrm{L}}-\mathrm{Q}_{\mathrm{j}}\end{array}$ & Energy balance at stage $\mathrm{j}$ \\
\hline $\begin{array}{l}\text { Pressure controller of the } \\
\text { extractive distillation column }\end{array}$ & $\mathrm{C}_{\mathrm{PC}-\mathrm{ED}}(\mathrm{t})=\mathrm{K}_{\mathrm{c}}\left(\mathrm{P}(\mathrm{t})-\mathrm{P}_{0}\right)+\frac{1}{\tau_{\mathrm{I}}} \int_{0}^{\mathrm{t}}\left(\mathrm{P}(\mathrm{t})-\mathrm{P}_{0}\right) \mathrm{dt}+\mathrm{P}_{0}$ & \\
\hline $\begin{array}{l}\text { Temperature controller of the } \\
\text { extractive distillation column }\end{array}$ & $\mathrm{C}_{\mathrm{TC}-\mathrm{ED}}(\mathrm{t})=\mathrm{K}_{\mathrm{c}}\left(\mathrm{T}_{0}-\mathrm{T}(\mathrm{t})\right)+\frac{1}{\tau_{\mathrm{I}}} \int_{0}^{\mathrm{t}}\left(\mathrm{T}_{0}-\mathrm{T}(\mathrm{t})\right) \mathrm{dt}+\mathrm{T}_{0}$ & \\
\hline $\begin{array}{l}\text { Bottom level controller of the } \\
\text { extractive distillation column }\end{array}$ & $\mathrm{C}_{\mathrm{LC}-\mathrm{ED}}(\mathrm{t})=\mathrm{K}_{\mathrm{c}}\left(\operatorname{Le}(\mathrm{t})-\mathrm{Le}_{0}\right)+\frac{1}{\tau_{\mathrm{I}}} \int_{0}^{\mathrm{t}}\left(\operatorname{Le}(\mathrm{t})-\mathrm{Le}_{0}\right) \mathrm{dt}+\mathrm{Le}_{0}$ & \\
\hline \multirow{3}{*}{$\begin{array}{l}\text { Solvent recovery column at } \\
\text { stage } \mathrm{j}\end{array}$} & $\frac{\mathrm{dM}_{\mathrm{j}}^{\prime}}{\mathrm{dt}}=\mathrm{V}_{\mathrm{j}+1}^{\prime}-\mathrm{V}_{\mathrm{j}}^{\prime}+\mathrm{L}_{\mathrm{j}-1}^{\prime}-\mathrm{L}_{\mathrm{j}}^{\prime}+\mathrm{F}_{\mathrm{j}}^{\prime}-\mathrm{S}_{\mathrm{j}}^{\prime} \mathrm{V}-\mathrm{S}_{\mathrm{j}}^{\mathrm{L}}$ & Total mass balance at stage $\mathrm{j}$ \\
\hline & $\begin{array}{l}\frac{d M_{j}^{\prime} x_{i, j}^{\prime}}{d t}=V_{j+1}^{\prime} y_{i, j+1}^{\prime}-V_{j}^{\prime} y_{i, j}^{\prime}+L_{j-1}^{\prime} x_{i, j-1}^{\prime}- \\
L_{J}^{\prime} x_{i, j}^{\prime}+F_{j}^{\prime} z_{i}^{\prime}-S_{j}^{\prime} y_{i, j}^{\prime}-S_{j}^{\prime} x_{i, j}^{\prime}\end{array}$ & $\begin{array}{l}\text { Component mass balance at } \\
\text { stage } \mathrm{j}\end{array}$ \\
\hline & 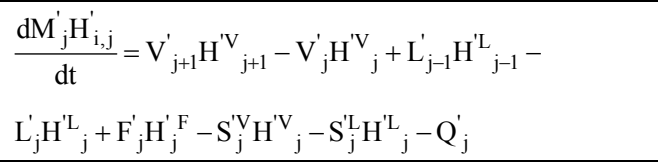 & Energy balance at stage $\mathrm{j}$ \\
\hline $\begin{array}{l}\text { Pressure controller of the } \\
\text { solvent recovery column }\end{array}$ & $\mathrm{C}_{\mathrm{PC}-\mathrm{SR}}(\mathrm{t})=\mathrm{K}_{\mathrm{c}}\left(\mathrm{P}^{\prime}(\mathrm{t})-\mathrm{P}_{0}^{\prime}\right)+\frac{1}{\tau_{\mathrm{I}}} \int_{0}^{\mathrm{t}}\left(\mathrm{P}^{\prime}(\mathrm{t})-\mathrm{P}_{0}^{\prime}\right) \mathrm{dt}+\mathrm{P}_{0}^{\prime}$ & \\
\hline $\begin{array}{l}\text { Overhead level controller of the } \\
\text { solvent recovery column }\end{array}$ & $\begin{array}{l}\mathrm{C}_{\mathrm{OLC}-\mathrm{SR}}(\mathrm{t})=\mathrm{K}_{\mathrm{c}}\left(\mathrm{Le}_{\mathrm{Ov}}^{\prime}(\mathrm{t})-\mathrm{Le}_{\mathrm{Ov} 0}^{\prime}\right)+ \\
\frac{1}{\tau_{\mathrm{I}}} \int_{0}^{\mathrm{t}}\left(\mathrm{Le}_{\mathrm{Ov}}^{\prime}(\mathrm{t})-\mathrm{Le}_{\mathrm{Ov} 0}^{\prime}\right) \mathrm{dt}+\mathrm{Le}_{\mathrm{Ov} 0}^{\prime}\end{array}$ & \\
\hline $\begin{array}{l}\text { Bottom level controller of the } \\
\text { solvent recovery column }\end{array}$ & $\begin{array}{l}\mathrm{C}_{\mathrm{BLC}-\mathrm{ED}}(\mathrm{t})=\mathrm{K}_{\mathrm{c}}\left(\mathrm{Le}_{\mathrm{B}}^{\prime}(\mathrm{t})-\mathrm{Le}_{\mathrm{B} 0}^{\prime}\right)+ \\
\frac{1}{\tau_{\mathrm{I}}} \int_{0}^{\mathrm{t}}\left(\mathrm{Le}_{\mathrm{B}}^{\prime}(\mathrm{t})-\mathrm{Le}_{\mathrm{B} 0}^{\prime}\right) \mathrm{dt}+\mathrm{Le}_{\mathrm{B} 0}^{\prime}\end{array}$ & \\
\hline \multirow{4}{*}{ Solvent recovery vessel } & $\frac{\mathrm{dM}}{\mathrm{dt}}=\mathrm{F}-\mathrm{R}-\mathrm{E}$ & Total mass balance \\
\hline & $\frac{\mathrm{dM}_{\mathrm{i}}}{\mathrm{dt}}=\mathrm{Fz}_{\mathrm{i}}-\mathrm{Rx}_{\mathrm{i}}-\mathrm{Ey}_{\mathrm{i}}$ & Component mass balance \\
\hline & $\sum_{i=1}^{n} x_{i}=1, \quad \sum_{i=1}^{n} y_{i}=1$ & Stoichiometric constraints \\
\hline & $\begin{array}{l}\sum_{\mathrm{i}=1}^{\mathrm{n}} \mathrm{M}_{\mathrm{i}} \mathrm{Cp} \mathrm{p}_{\mathrm{i}} \frac{\mathrm{dT}}{\mathrm{dt}}=\mathrm{F} \sum_{\mathrm{i}=1}^{\mathrm{n}} \mathrm{Z}_{\mathrm{i}} \mathrm{Cp} \mathrm{p}_{\mathrm{i}}\left(\mathrm{T}-\mathrm{T}_{\mathrm{O}}\right)- \\
\mathrm{R} \sum_{\mathrm{i}=1}^{\mathrm{n}} \mathrm{x}_{\mathrm{i}} \mathrm{Cp} \mathrm{p}_{\mathrm{i}}\left(\mathrm{T}-\mathrm{T}_{\mathrm{O}}\right)-\mathrm{E} \sum_{\mathrm{i}=1}^{\mathrm{n}} \mathrm{y}_{\mathrm{i}} \mathrm{Cp} \mathrm{p}_{\mathrm{i}}\left(\mathrm{T}-\mathrm{T}_{\mathrm{O}}\right)\end{array}$ & Energy balance \\
\hline
\end{tabular}




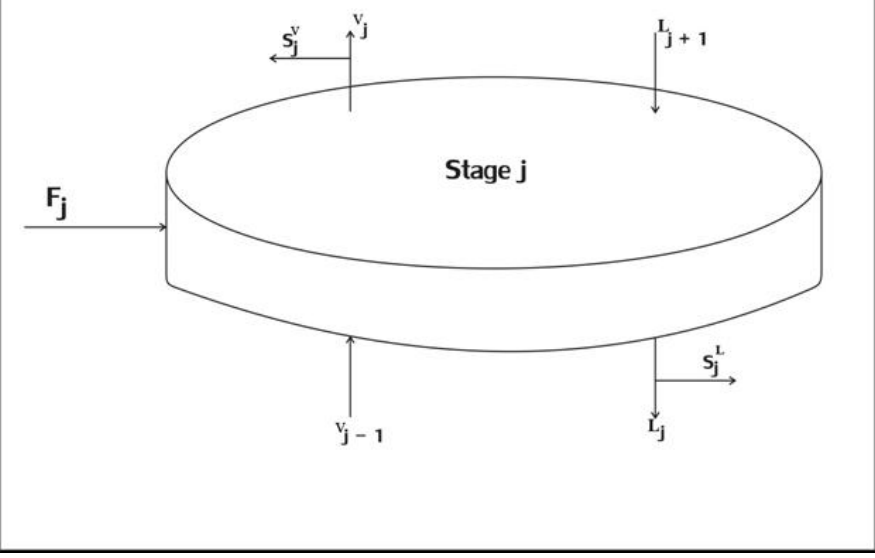

Figure 3: Schematic of jth tray of a multicomponent tower.

\section{OPTIMIZATION}

Chemical engineering processes are typically influenced by a variety of uncertain parameters. In a continuous distillation process, steady-state conditions should represent the optimal operation mode. If the process reaches steady-state in the shortest possible period, the amount of undesired products (off-spec) would become lower while all the operating parameters would reach their optimum value.

A general dynamic optimization problem has the following mathematical definition:

\section{Minimize}

$f(u)=\Theta\left[v\left(t_{f}\right)\right]+\int_{t_{0}}^{t_{f}} \Phi(v(t), u(t), t) d t$

Subject to

$\theta\left(v^{\bullet}, v, u, t\right)=0$

$v_{\min } \leq v \leq v_{\max }$

$\mathrm{u}_{\min } \leq \mathrm{u} \leq \mathrm{u}_{\max }$

$v\left(t_{0}\right)=v_{0}$

The starting point, $\mathrm{v}\left(\mathrm{t}_{0}\right)$, should be known and $\Theta$ and $\Phi$ are assumed to be continuous with continuous first particular derivatives (with respect to $\mathrm{v}(\mathrm{t}), \mathrm{u}(\mathrm{t})$ and $t$ ). The independent variable in this problem is time, t (Edgar and Himmelblau (1989)). In an optimization problem, objective function selection is an important step, as detailed in the following section.

\section{Optimization Problem Definition}

The target of the optimization in the present study would be to determine the parameters of controllers in the extractive distillation section for a given disturbances during the unsteady-state operation of the unit by minimizing the difference between the process value and the set point of the controller in the shortest possible time. Therefore, the objective function in the optimization problem could be defined as the sum of squared errors as follows:

Minimize $\sum_{i=1}^{n}$ ISE

where

$\mathrm{ISE}=\int_{0}^{t_{\mathrm{F}}}\left(\frac{\mathrm{PV}-\mathrm{SP}}{\mathrm{SP}}\right)^{2} \mathrm{dt}$

Decision variables in this problem were set to be constants of the controllers (i.e., $\mathrm{K}_{\mathrm{c}}$ and $\tau_{\mathrm{I}}$ ). Comparing Eq. (6) with the general problem 
definition in Eq. (1) reveals that, in the present problem, $\Theta=0$ and $\Phi=\left(\frac{\mathrm{PV}-\mathrm{SP}}{\mathrm{SP}}\right)^{2}$

\section{Optimization Problem Solution}

Dynamic optimization problems could be solved by either deterministic or stochastic approaches. In this study, stochastic methods and more precisely the Nelder-Mead algorithm (Mathews and Fink, 2004) has been adopted for solving the optimization problem. Nelder-Mead is a direct search method of nonlinear optimization that works moderately well for stochastic problems. This method attempts to minimize a scalar-valued nonlinear function of $\mathrm{n}$ real variables using only function values, without any derivative information. Like all general purpose multidimensional optimization algorithms, NelderMead occasionally reaches a local optimum instead of finding the global solution. The standard approach to carry on is to restart the algorithm with a new simplex starting at the current best value (Mathews and Fink (2004)).

\section{RESULTS AND DISCUSSION}

The results of steady state and dynamic modeling and optimization are detailed in the following sections:

\section{Steady-State Simulation}

In the absence of reliable data for the unsteadystate operation of the real plant, steady-state response of the model was used to examine the performance of the model. In order to obtain the steady-state conditions of the process, response of the dynamic simulation after long enough time was gathered, when the time derivatives in the model equations were vanished. The model was solved for the operating conditions shown in Table 3 and some of the corresponding steady-state results are shown in Table 4 . As seen in these tables, some variables have large relative errors but they are insignificant and there is a good agreement between the results of the model and actual plant data.

Table 3: Parameters used in modeling of the benzene extractive distillation section

\begin{tabular}{|c|c|c|}
\hline Parameter & Value & Unit \\
\hline No. of extractive distillation column trays & 30 & - \\
\hline Distillate rate & 840.5 & $\mathrm{~kg} / \mathrm{hr}$ \\
\hline Feed pressure & 7.1 & bar \\
\hline Feed temperature & 81 & ${ }^{\circ} \mathrm{C}$ \\
\hline Solvent pressure & 2.1 & bar \\
\hline Solvent temperature & 90 & ${ }^{\circ} \mathrm{C}$ \\
\hline Feed tray & 17 & - \\
\hline Solvent tray & 1 & - \\
\hline Overhead pressure & 2.1 & bar \\
\hline Overhead temperature & 110 & ${ }^{\circ} \mathrm{C}$ \\
\hline Bottom pressure & 2.63 & bar \\
\hline Bottom temperature & 156 & ${ }^{\circ} \mathrm{C}$ \\
\hline No. of solvent recovery column trays & 11 & - \\
\hline Distillate rate & 827.05 & $\mathrm{~kg} / \mathrm{hr}$ \\
\hline Feeds tray & 11 & - \\
\hline Overhead pressure & 1.2 & bar \\
\hline Overhead temperature & 79 & ${ }^{\circ} \mathrm{C}$ \\
\hline Bottom pressure & 1.25 & bar \\
\hline Bottom temperature & 92 & ${ }^{\circ} \mathrm{C}$ \\
\hline Reflux ratio & 0.51 & - \\
\hline Solvent recovery bottom pump discharge pressure & 8.7 & bar \\
\hline
\end{tabular}


Table 4: Comparison between calculated and actual value in the extractive distillation and solvent recovery columns

\begin{tabular}{|c|c|c|c|c|}
\hline Section & Parameter & $\begin{array}{c}\text { Calculated } \\
\text { value }\end{array}$ & $\begin{array}{c}\text { Actual } \\
\text { value }\end{array}$ & $\begin{array}{c}\text { Relative error } \\
(\%)\end{array}$ \\
\hline \multirow{8}{*}{$\begin{array}{l}\text { Extractive } \\
\text { distillation column }\end{array}$} & Distillate mass flow $(\mathrm{kg} / \mathrm{hr})$ & 840.50 & 841.36 & -0.10 \\
\hline & Bottom mass flow $(\mathrm{kg} / \mathrm{hr})$ & 34372.83 & 34174.18 & 0.58 \\
\hline & Split fraction of cyclohexane in distillate & 1 & 1 & 0 \\
\hline & Split fraction of cyclohexane in bottom & 0 & 0 & \\
\hline & Split fraction of benzene in distillate & 0.04 & 0.05 & -20 \\
\hline & Split fraction of benzene in bottom & 0.95 & 0.99 & -4 \\
\hline & Temperature of overhead stream $\left({ }^{\circ} \mathrm{C}\right)$ & 111.32 & 110 & 1.20 \\
\hline & Temperature of bottom stream $\left({ }^{\circ} \mathrm{C}\right)$ & 157.12 & 156 & 0.72 \\
\hline \multirow{8}{*}{$\begin{array}{l}\text { Solvent recovery } \\
\text { column }\end{array}$} & Distillate mass flow $(\mathrm{kg} / \mathrm{hr})$ & 827.80 & 827.01 & 0.09 \\
\hline & Bottom mass flow $(\mathrm{kg} / \mathrm{hr})$ & 2587.39 & 2605.20 & -0.68 \\
\hline & Split fraction of cyclohexane in distillate & 1 & 1 & 0 \\
\hline & Split fraction of cyclohexane in bottom & 0 & 0 & - \\
\hline & Split fraction of NFM in distillate & 0 & 0 & - \\
\hline & Split fraction of NFM in bottom & 1 & 1 & 0 \\
\hline & Temperature of overhead stream $\left({ }^{\circ} \mathrm{C}\right)$ & 75.50 & 79 & -4.42 \\
\hline & Temperature of bottom stream $\left({ }^{\circ} \mathrm{C}\right)$ & 96.25 & 92 & 4.61 \\
\hline
\end{tabular}

\section{Case Studies}

Effect of changes in some key parameters on the behavior of the synthesis section was investigated based on the model developed in this work. Some of these case studies are given below.

\section{a) Effect of NFM Feed Temperature}

Effect of NFM feed temperature on the recovery of benzene is shown in Figure 4. Recovery of benzene is increased slightly between 60 and $90{ }^{\circ} \mathrm{C}$, beyond which there is a sharp decrease in the recovery with an increase in the temperature. An increase in NFM feed temperature causes an increase in vapor flow due to an increase in the aromatics at the top product. At low NFM feed temperature, heavy non-aromatics would condense and partially enter the benzene stream in the stripper. Therefore, NFM feed temperature should be $90{ }^{\circ} \mathrm{C}$ to ensure that the heavy non-aromatics will exit the top of the extractive distillation column without lowering the benzene recovery.

\section{b) Effect of Solvent to Feed Ratio}

Operating cost of the extractive distillation unit depends mainly on the solvent to feed ratio since increasing the solvent results in an increase in the energy consumption. Effect of solvent to feed ratio on the recovery of benzene is shown in Figure 5. As shown in this figure, benzene recovery is increased upon increasing the solvent to feed ratio up to 3.5, after which the recovery of benzene becomes constant. The adequate amount of aromatic must be in the vapor to avoid phase separation in the extractive distillation column in order for the phases to be mixed completely. Consequently, the favored solvent to feed ratio should be in the vicinity of 3.5.

\section{Dynamic Simulation}

Figures 6a-d illustrate the changes in the extractive distillation column conditions (bottom liquid level, temperature, pressure and benzene recovery) when the flow rate of the solvent is increased by $15 \%$ for 30 minutes after the first twenty minutes. Due to an increase in the flow rate of the cold solvent, the amount of condensed vapor and the hydrocarbon dissolved in the solvent is increased. Therefore, the amount of vapor in the overhead of the column decreases and the pressure in this section decreases (Figure 6a). Since the quantity of the cold solvent at the top of the column is increased, the temperature also decreases as a result (Figure 6c). The temperature controller distinguishes a decrease in temperature, which increases reboiler duty; as a result, vapor flow rate, the overhead pressure and temperature increase. As the solvent is separated at the bottom of the column, increasing the solvent first causes an increase in bottom liquid level. Then, by an increase in reboiler duty and vaporization of liquid, the liquid level returns to its initial point (Figure 6b). The effect of increasing the solvent flow rate on benzene recovery is shown in Figure 6d. Initially, separation of benzene will be increased by increasing the flow rate 
of the solvent. However, since the overhead temperature is decreased (see Figure 6c), duty of the reboiler is increased, resulting in a decrease in the benzene recovery, as illustrated in Figure 6d.

It should also be mentioned that the optimization was carried out for some other parameters such as feed temperature or any other changes in feed flow rate. With different disturbances like pulse function rather than a step function, different results may be obtained with similar trends. The model was, of course, solved for different disturbances and only part of the results presented here in order to keep the paper clear and concise since other disturbances did not add new information because the trends are rather similar. When a pulsed disturbance is imposed on the process, one can better monitor the actions of the controllers in the return path too. Since experimental data were not available for the new steady state that resulted from the step input for the validation purposes, the pulse function is used since the end point validation of the system was possible.

\section{Dynamic Optimization}

In this section the time dependent profiles of the parameters of the controllers (i.e., $\mathrm{K}_{\mathrm{c}}$ and $\tau_{\mathrm{I}}$ ) during transition from one steady-state condition to another

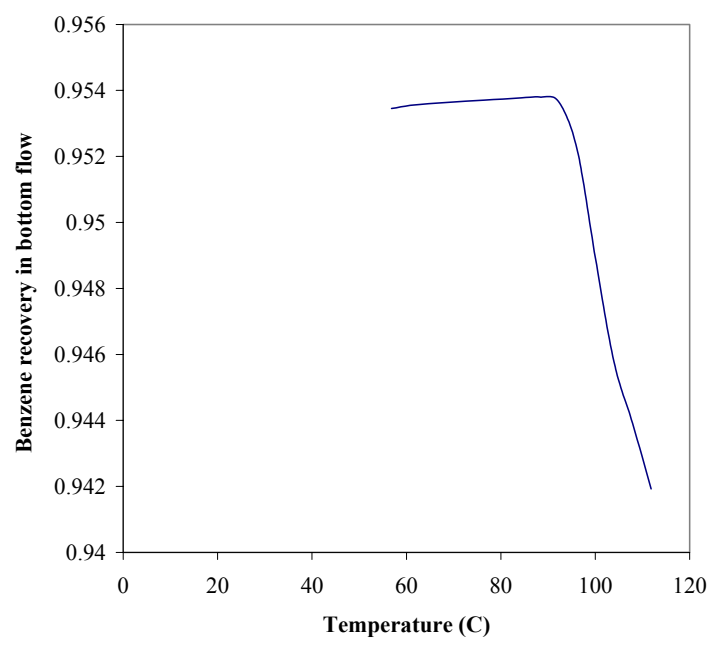

Figure 4: Effect of NFM feed temperature on benzene recovery were determined by minimizing the deviation of key operating variables from their corresponding set points [Eq. (7)]. In order to estimate the optimized constants, each controller was optimized separately with constants of the other controllers assumed to be unchanged. Final optimized constants of all controllers were found by applying the optimization algorithm, taking these estimates as initial guess and letting the constants of all controllers be changed during the optimization.

Optimized constants of the controllers as well as the corresponding constants before optimization are listed in Table 5. Figures 7a-d illustrate the changes in the extractive distillation conditions with optimized constants of the controllers when the flow rate of the solvent to the extractive distillation column is increased by $15 \%$ for 30 minutes. Comparing these figures with Figures 6a-d (dynamic changes of the same parameters using constants of the controllers before optimization) clearly reveals that the controllers with optimized constants respond much faster and the process reaches steady-state almost immediately. In fact, optimized controllers of the extractive distillation column are so very fast that the solvent recovery column does not sense such a small deviation from steady-state. This procedure could be applied in the advanced process control of the unit in order to reduce off-spec products of the unit.

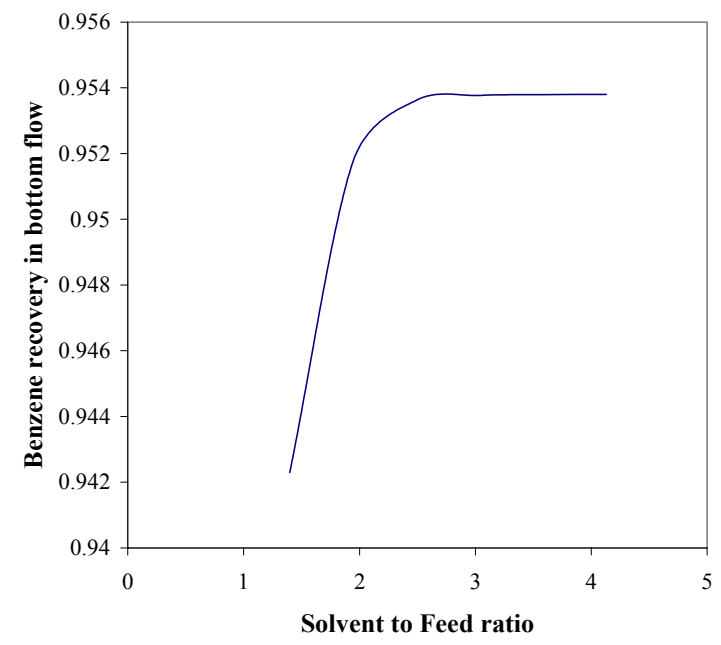

Figure 5: The effect of solvent to feed ratio on benzene recovery 


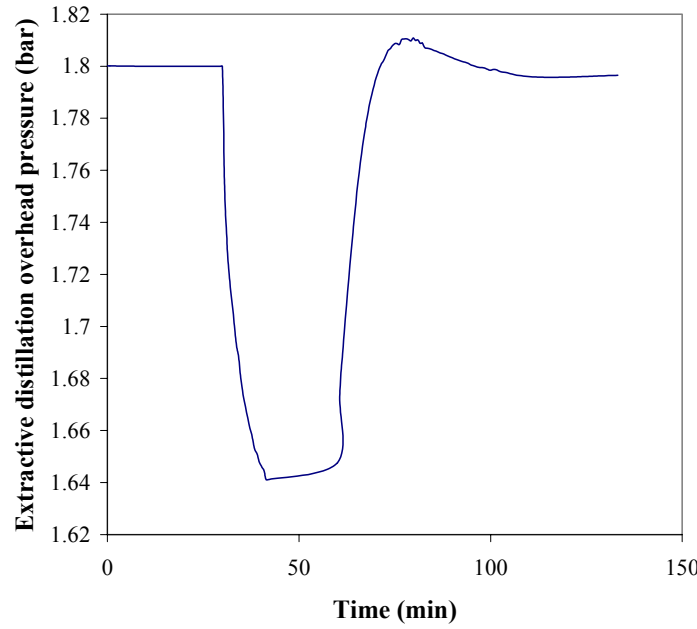

(a)

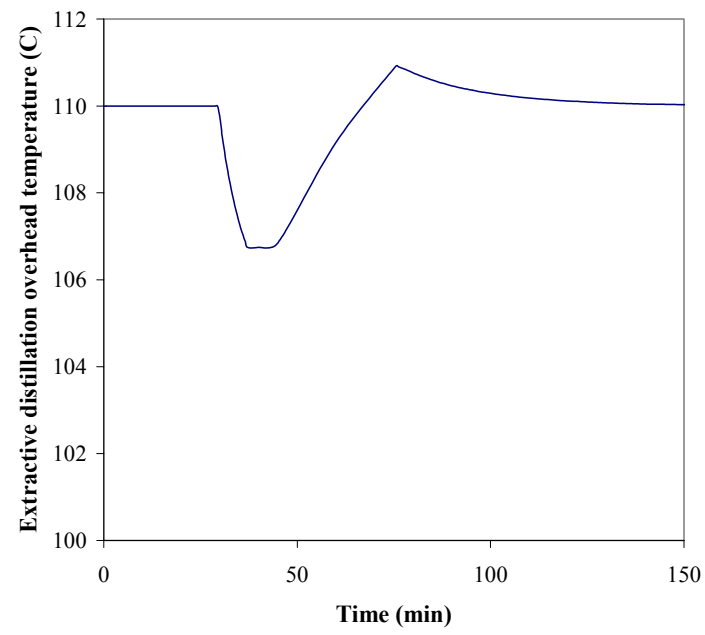

(c)

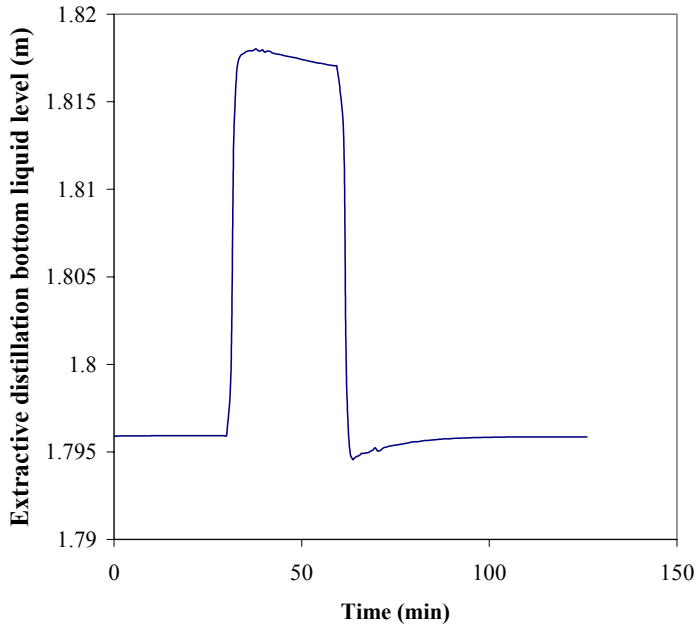

(b)

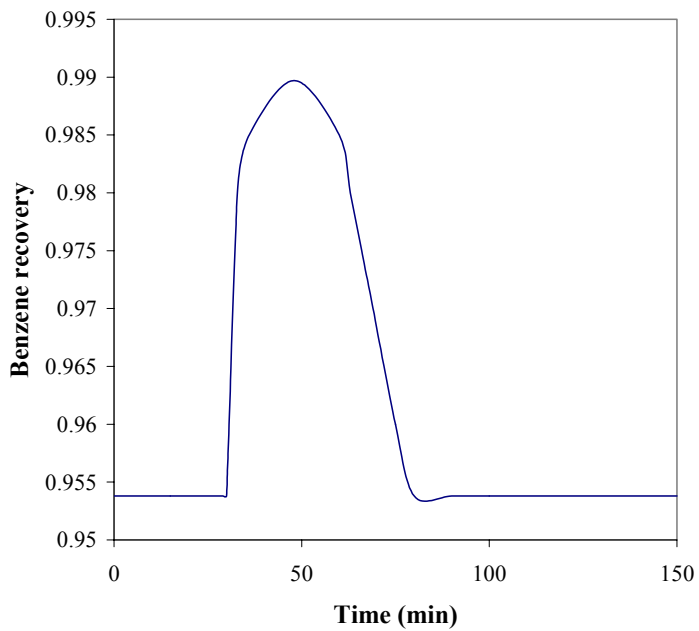

(d)

Figure 6: effect of increasing the flow rate of solvent on (a) Extractive distillation overhead pressure.

(b) Extractive distillation bottom liquid level. (c) Extractive distillation overhead temperature.

(d) Benzene recovery, using non-optimized controllers' constants.

Table 5: Initial and optimized constants of the controllers

\begin{tabular}{|l|c|c|c|c|}
\hline \multirow{2}{*}{ Controller } & \multicolumn{2}{|c|}{ Initial } & \multicolumn{2}{c|}{ Optimized } \\
\cline { 2 - 4 } & $\mathbf{K}_{\mathbf{C}}$ & $\boldsymbol{\tau}_{\mathbf{I}}$ & $\mathbf{K}_{\mathbf{C}}$ & 2.03 \\
\hline $\begin{array}{l}\text { Pressure controller of the } \\
\text { extractive distillation column }\end{array}$ & 100 & 2.25 & 20.42 & 1 \\
$\begin{array}{l}\text { Temperature controller of the } \\
\text { extractive distillation column }\end{array}$ & 85 & 3 & 9.89 & 2.05 \\
$\begin{array}{l}\text { Bottom level controller of the } \\
\text { extractive distillation column }\end{array}$ & 30 & 0.02 & 15.39 & 12.06 \\
$\begin{array}{l}\text { Pressure controller of the solvent } \\
\text { recovery column }\end{array}$ & 100 & 2.25 & 20.07 & 2.07 \\
$\begin{array}{l}\text { Overhead level controller of the } \\
\text { solvent recovery column }\end{array}$ & 30 & 0.02 & 8.45 & 55.88 \\
$\begin{array}{l}\text { Bottom level controller of the } \\
\text { solvent recovery column }\end{array}$ & 30 & 0.02 & 10.13 & \\
\hline
\end{tabular}




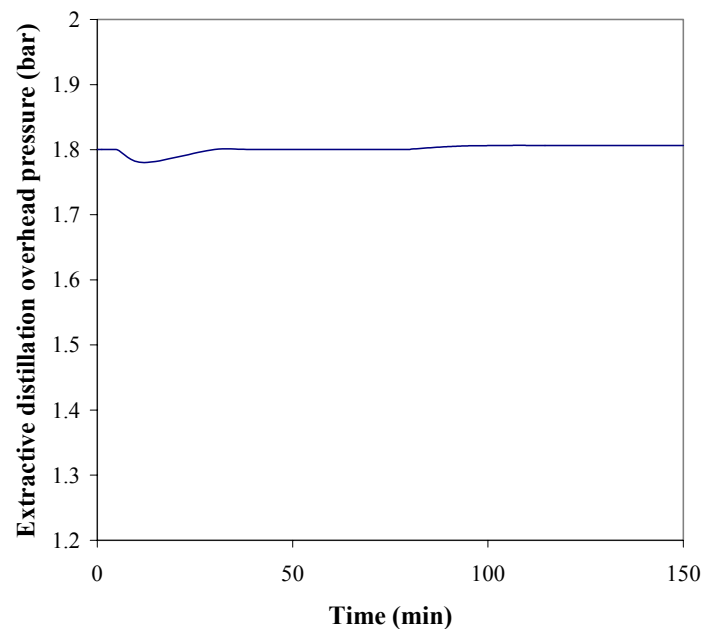

(a)

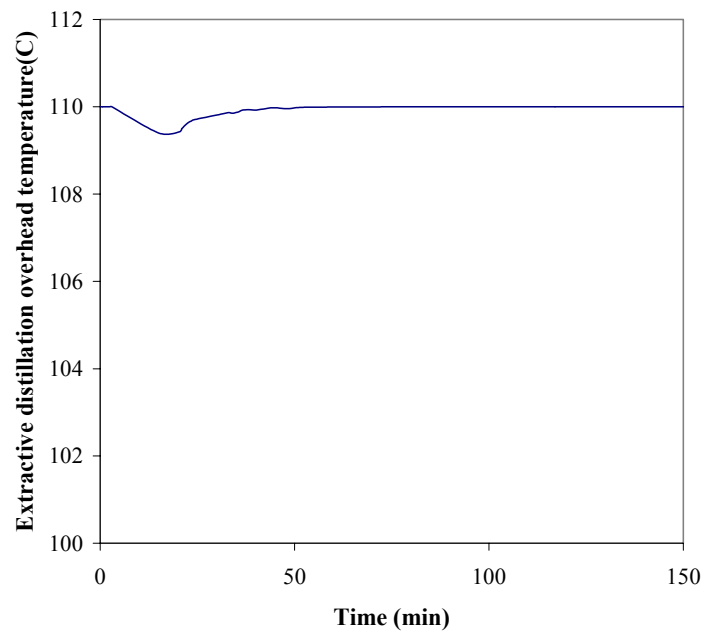

(c)

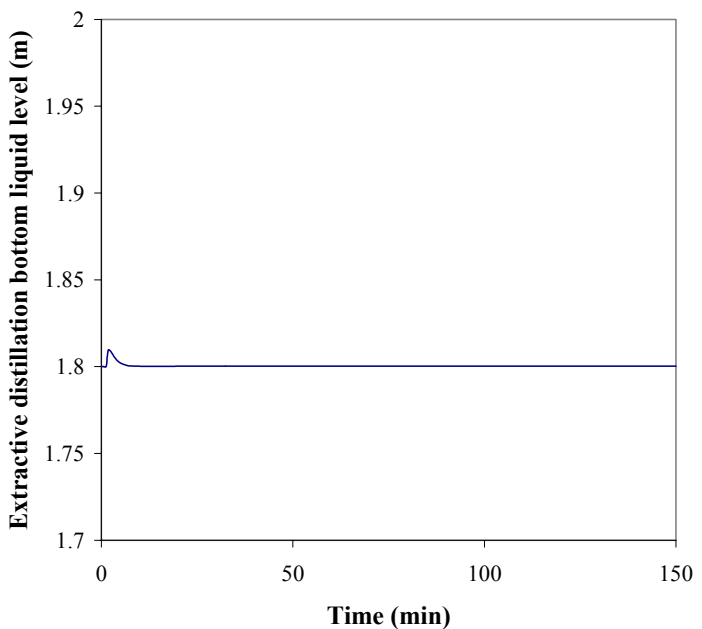

(b)

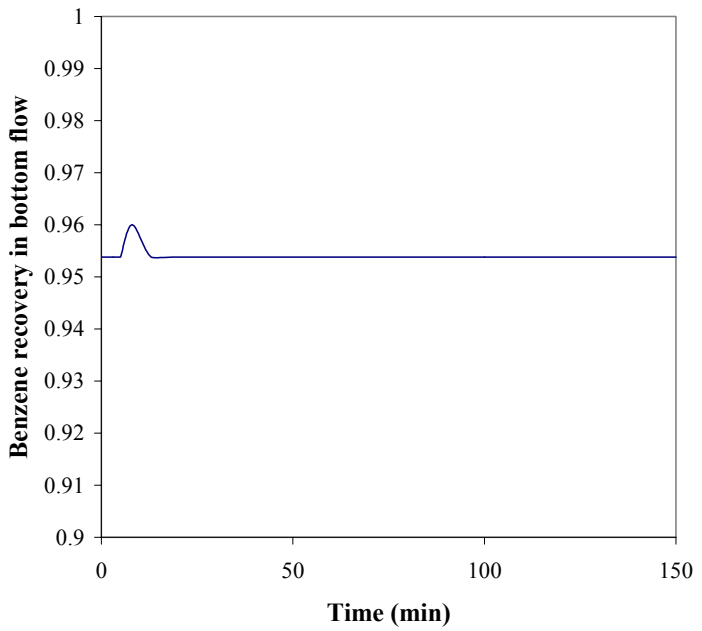

(d)

Figure 7: effect of increasing the flow rate of solvent on (a) Extractive distillation overhead pressure. (b) Extractive distillation bottom liquid level. (c) Extractive distillation overhead temperature with optimized controllers' constant. (d) Benzene recovery, using optimized controllers' constants.

\section{CONCLUSIONS}

A dynamic model was developed for the optimization of the industrial extractive distillation section of the benzene extraction plant. Since the dynamic model needs a good steady state model, the steady-state model was developed first and validated by using the actual plant data. Because the solvent to feed ratio and operating temperature are two important parameters in the benzene separation, the optimum solvent to feed ratio was determined under steady-state conditions. In dynamic simulation, the constants of the controllers of the unit were optimized to improve the controllability of the extractive distillation section and minimize deviations from the steady state, which is the best condition. It was shown that optimized variables would result in damping down of the changes to operating conditions very similar to those reached under the steady-state conditions.

\section{NOMENCLATURE}

C Controller's response

$\mathrm{C}_{\mathrm{p}} \quad$ Specific heat

E Heavy phase flow rate

F $\quad$ Feed flow rate

$\mathrm{F} \quad$ Objective function

$\mathrm{H} \quad$ Molar enthalpy

ISE Integrated squared error

K Distribution coefficient<smiles>[AlH2]</smiles>

$\mathrm{kJ} \mathrm{kg}^{-1} \mathrm{~K}^{-1}$ $\mathrm{kg} \mathrm{hr}^{-1}$ $\mathrm{kg} \mathrm{hr}^{-1}$ 


$\begin{array}{llr}776 & & \text { Azadeh Ghaee, } \mathrm{Rahmat} \mathrm{So} \\ \mathrm{K}_{\mathrm{C}} & \text { Controller gain } & (-) \\ \mathrm{L} & \text { Liquid flow rate } & \mathrm{kg} \mathrm{hr}^{-1} \\ \mathrm{Le} & \text { Level } & \mathrm{M} \\ \mathrm{Le} & \text { Steady state level } & \mathrm{M} \\ \mathrm{M} & \text { Hold up } & \mathrm{kg} \\ \mathrm{P} & \text { Pressure } & \mathrm{kPa} \\ \mathrm{P}_{\mathrm{C}} & \text { Critical pressure } & \mathrm{Bar} \\ \mathrm{P}_{0} & \text { Steady state pressure } & \mathrm{kPa} \\ \mathrm{PV} & \text { Process variable } & (-) \\ \mathrm{Q} & \text { Heat duty } & \mathrm{kJ} \mathrm{hr}^{-1} \\ \mathrm{R} & \text { Light phase flow rate } & \mathrm{kg} \mathrm{hr}^{-1} \\ \mathrm{~S} & \text { Side stream flow rate } & \mathrm{kg} \mathrm{hr}^{-1} \\ \mathrm{SP} & \text { Set point } & (-) \\ \mathrm{T} & \text { Temperature } & \mathrm{K} \\ \mathrm{T}_{\mathrm{NBP}} & \text { Normal boiling point } & \mathrm{K} \\ & \text { temperature } & \\ \mathrm{T}_{\mathrm{C}} & \text { Critical temperature } & \mathrm{K} \\ \mathrm{T}_{0} & \text { Steady state temperature } & \mathrm{K} \\ \mathrm{T} & \text { Time } & (-) \\ \mathrm{t}_{\mathrm{f}} & \text { Final time } & (-) \\ \mathrm{U} & \text { Control variable } & (-) \\ \mathrm{V} & \text { Vapor flow rate } & (-) \\ \mathrm{V} & \text { Operating variable } & (-) \\ \mathrm{V}_{0} & \text { Starting point } & (-) \\ \mathrm{X} & \text { Mass fraction in liquid phase } & (-) \\ \mathrm{Y} & \text { Mass fraction in vapor phase } & (-) \\ \mathrm{Z} & \text { Mass fraction in feed } & (-) \\ \Theta & \text { Steady state value } & (-) \\ \Theta & \text { Equality constraint function } & (-) \\ \Phi & \text { Deviation function } & (-) \\ \tau_{\mathrm{I}} & \text { Integral time } & \\ & & \mathrm{kg} \mathrm{hr}\end{array}$

\section{Subscript}

$\begin{array}{ll}\text { I } & \text { Component no. } \\ \text { J } & \text { Tray no. } \\ \text { Max } & \text { Maximum value } \\ \text { Min } & \text { Minimum value } \\ \text { Ov } & \text { Overhead } \\ \text { B } & \text { Bottom }\end{array}$

\section{Superscript}

$\begin{array}{ll}\text { L } & \text { Liquid } \\ \text { V } & \text { Vapor } \\ , & \text { Solvent recovery column }\end{array}$

\section{REFERENCES}

Edgar, T. F., Himmelblau D. M., "Optimization of Chemical Processes", McGraw-Hill, International Edition (1989).
Jimenez L., Costa-Lopez J.," The production of butyl acetate and methanol via reactive and extractive distillation. II. Process modeling, dynamic simulation, and control strategy", Industrial \& Engineering Chemistry Research, 41, 6735-6744 (2002).

Ko M., Lee. S, Cho J. and Kim. H., "Liquid-Liquid Equilibria for Binary Systems Containing NFormyl morpholine". Journal of Chemical and Engineering Data, 4, 923-926 (2002a).

Ko M., Lee S., Cho J. and Kim. H., "Simulation of the Aromatic Recovery Process by Extractive Distillation". Korean Journal of Chemical Engineering, 19 (2002b).

Langston.P., Hilal N., Shingfield.S., Webb.S., "Simulation and optimization of extractive distillation with water as solvent", Chemical Engineering and Processing, 44, 345-351 (2005).

Llano-Restrepo M., Aguilar-Arias J., "Modeling and simulation of saline extractive distillation columns for the production of absolute ethanol", Computers \& Chemical Engineering, 27, 527-549 (2003).

Low K H., Sorensen E.," Optimal operation of extractive distillation in different batch configurations", AICHE Journal, 48, 1034-1050 (2002).

Mathews J. H. and Fink K. K. "Numerical Methods Using Matlab", Prentice-Hall, Fourth Edition (2004).

Munoz R, Monton J. B., Burguet MC, de la Torre," Separation of isobutyl alcohol and isobutyl acetate by extractive distillation and pressureswing distillation: Simulation and optimization", Separation and Purification Technology, 50, 175183 (2006).

Pradhan S., Kannan A., "Simulation and analysis of extractive distillation process in a valve tray column using the rate based model", Korean Journal of Chemical Engineering, 22, 441-451 (2005).

Steltenpohl P., Chlebovec M., Graczova E.," Simulation of toluene extractive distillation from a mixture with heptane", Chemical PapersChemicke Zvesti, 59, 421-427 (2005).

Wauquier.J. P.,"Crude Oil Petroleum Products, Process Flow sheets", IFP, Edition Technip (1995).

Wozny G., Li P., "Optimization and experimental verification of startup policies for distillation columns", Computers and Chemical Engineering, 28, 253-265 (2004). 